\title{
Review of Window and Filter Requirements for Commissioning of the Advanced Photon Source Insertion Device Beamlines
}

\section{Tuncer M. Kuzay and Zhibi Wang Experimental Facilities Division}

\section{DISCLAIMER}

This report was prepared as an account of work sponsored by an agency of the United States Government. Neither the United States Government nor any agency thereof, nor any of their employees, makes any warranty, express or implied, or assumes any legal liability or responsibility for the accuracy, completeness, or usefulness of any information, apparatus, product, or process disclosed, or represents that its use would not infringe privately owned rights. Reference herein to any specific commercial product, process, or service by trade name, trademark, manufacturer, or otherwise does not necessarily constitute or imply its endorsement, recommendation, or favoring by the United States Government or any agency thereof. The views and opinions of authors expressed herein do not necessarily state or reflect those of the United States Government or any agency thereof.

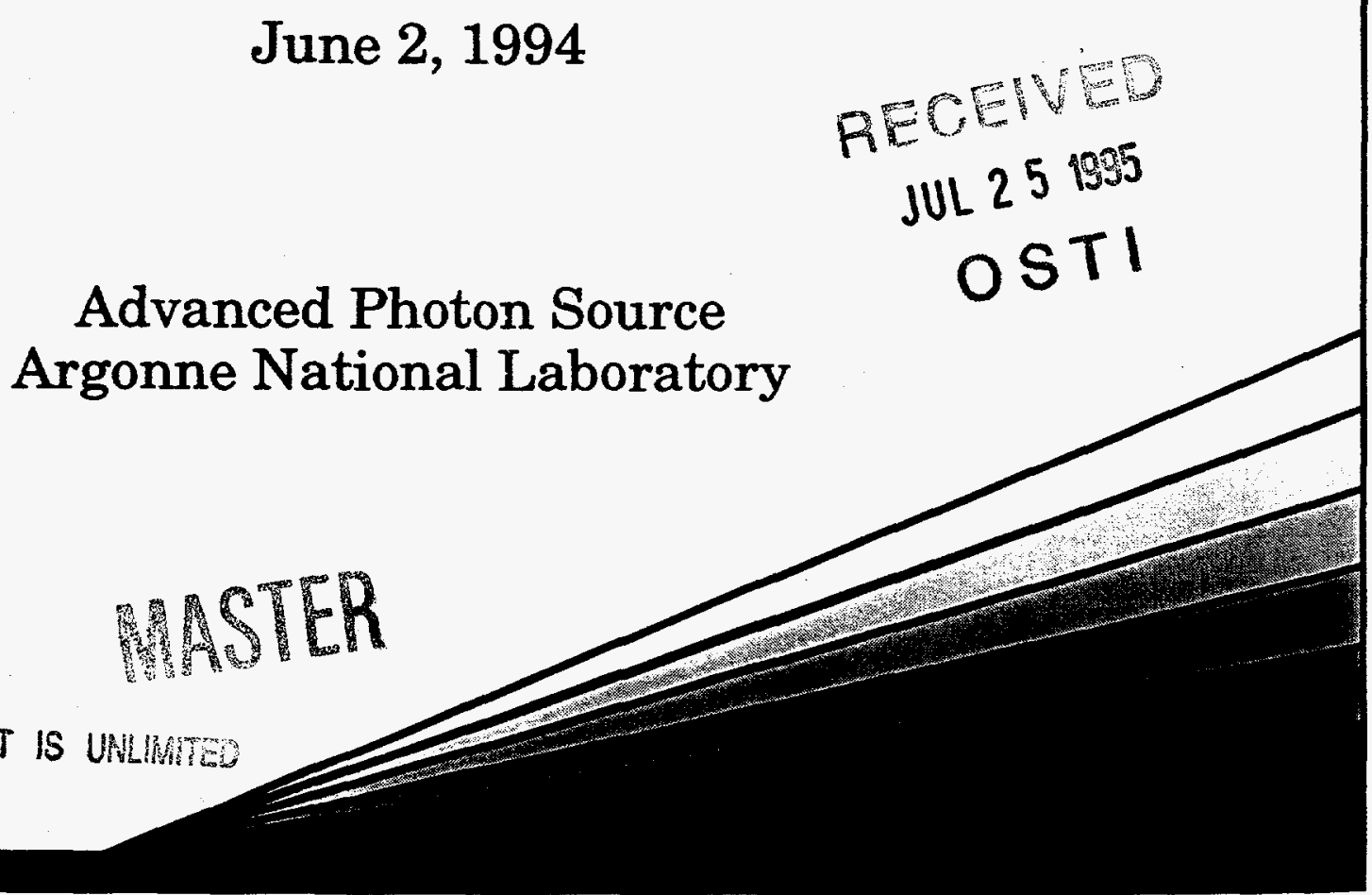




\section{DISCLAIMER}

Portions of this document may be illegible in electronic image products. Images are produced from the best available original document. 


\title{
Review of Window and Filter Requirements for Commissioning of the Advanced Photon Source Insertion Device Beamlines
}

\author{
Tuncer M. Kuzay and Zhibi Wang \\ Advanced Photon Source \\ Argonne National Laboratory \\ 9700 S. Cass Avenue \\ Argonne, Illinois 60439
}

\section{Introduction}

The Advanced Photon Source (APS) is building 16 insertion device (ID) front ends for the first phase of the project. Eleven of these are to be equipped with the APS Undulator A and the other five with a Wiggler-A-type source. The Undulator A front ends are designed to operate in a "windowless" mode using an APS-designed differential pump. However, during beamline commissioning and early operations of the storage ring, it is prudent to install windows to ensure storage ring vacuum safety before easing into windowless operation. However, the window designed for this interim period may not meet all the needs of a user's scientific program. In the early phases of the project through commissioning and start of operations, such a window will permit the user to prepare for his program, while allowing both the user and the facility operators to gain experience for safe phasing into eventual windowless operations. In this report, we will present analysis and design options for a variety of windows particularly suited to either the APS Undulator A front ends or as user windows located in the first optics enclosure (FOE). 
All analyses are done for a filter and a window located at their normal distance from the source in the insertion device (ID) front end. When a user filter/window combination is analyzed, then the distance from the source is the location of the front end differential pump outside the shield wall. This increase in distance eases the filter thermo-structural problems somewhat but does not impact the results for the window.

The window is a physical vacuum barrier between two beam transport regions with two different levels of vacuum. Therefore, it protects one side against accidental or unwanted vacuum excursions from the other side. The window material is chosen to be transparent to $\mathrm{x}$-rays. As such, low- $\mathrm{Z}$ materials are preferred; beryllium is a very common window material. In conventional synchrotron applications, a foil of special grade Be, which is better than $99.8 \%$ pure and is $250 \mu \mathrm{m}$ (10 mil) thick, is often used as the window material. This Be foil is metallurgically bonded to a water-cooled copper Conflat flange. Several reputable U.S. and European manufacturers of Be windows can provide window assemblies, 125 to $250 \mu \mathrm{m}$ thick, that are warranted to be vacuum tight. Another window material considered is the CVD diamond. Both materials have been the subject of extensive analytical studies at the APS.

Windows generally fail under several scenarios. These include severe vacuum incursions (an atmospheric shock wave being the worst possible case), oxidization of Be itself coming in contact with air or oxygen containing impure gases, and deterioration of the window braze itself. However, thermally induced failures under $x$-ray heating of the Be foil is the most recognized and studied case of window failures. Structural failure of the thin Be foil under heating and the associated thermal stresses have been poorly understood. It is now clear that using half the foil yield strength as the limiting thermally induced shear stress has predicted early failures in Be windows. Depending on the use and power of the source, etc., the 
window failures may occur as sudden cracking under heat, gradual evaporative erosion, or elastic/plastic buckling. The latter scenario has been experimentally observed, and we have verified it analytically [1].

The thermo-structural analysis of the window is often very complex and, depending on the ID source, may involve concurrent filter analysis. For a proper filter/window analysis, the $\mathrm{x}$ ray source spectra should be correctly represented, the filter/window absorption should be correctly accounted for over the energy spectra of the beam, and finally, realistic structural failure criteria should be postulated for the window. This last point cannot be overemphasized. The prediction of the temperature field in a filter/window is usually reliable because it is essentially a conduction problem (radiation is a minor issue in the window, although it can be substantial for an uncooled filter). Thermal codes (such as ANSYS or ALGOR) and simpler closed-form solutions often agree closely in predicting the temperature field. However, addressing correct stress criteria for failure or safe design conditions is difficult and requires very complex and careful analysis.

Windows are often protected from the beam power by introducing filters in the path of the radiation to protect the windows from excessive heat loads or heat fluxes. The thermal and the structural analyses of the filter and window are very similar, although the analysis is much less stringent for a filter than it is for a window. Filters are not vacuum seals unlike windows. Neither do they necessarily have to be convectively cooled; often radiative cooling is the only mode of cooling used. A filter failure is not regarded as catastrophic. A common feature for both the filter and window is that the initiation of their failure is very hard, if not impossible, to detect. Hence, both structures should be conservatively designed and engineered for reliable operation. Problems are particularly acute with the APS Undulator A white beam. We have expended great effort to develop sophisticated analytical tools to handle the filter/window problem subject to the white beam from the APS IDs. This has culminated in the development of the XRAP code [2] as briefly described below. 


\section{X-Ray Absorption Package (XRAP) [2]}

XRAP is a code developed for analysis of optical elements in synchrotron radiation facilities. It has many unique features that are not available in existing software packages. It aims to solve two problems: 1) generating bending magnet (BM) and insertion device (ID) spectra and calculating their absorption in media, especially in some tailored structural forms, such as variable-thickness windows, filters, and crystals; and 2) providing a finite difference technique that performs fast and sophisticated thermal and stress analyses for such optical elements. For very complex geometries, an interface is provided to directly connect XRAP to a finite element code such as ANSYS.

Some of the features built into XRAP include: (1) generation of bending magnet, wiggler, and undulator spectra; (2) photon absorption analysis of optical elements including filters, windows, and mirrors, etc.; (3) thermal and stress analyses of filters and windows with variable cross sections; (4) buckling analysis of the optics, filters, and windows under thermal loading from the absorbed power; (5) absorption of photons in the inclined geometry in both the horizontal and vertical orientations; (6) reflectivity and power absorption calculations in a mirror; (7) spectral throughput for each optical element; (8) capability to interface with finite element codes such as ANSYS for the thermal and structural analysis of beamline components with complex geometry; (9) a user friendly graphical interface based on the $\mathrm{X}$-window system as shown in Figure 1; and (10) postscript file output of either black/white or colored graphics for total or absorbed power, temperature, stress, spectra, etc.

For thermal analysis, radiation cooling is allowed. The thermal expansion coefficient and thermal conductivity can be temperature dependent. Regardless of these nonlinearities introduced, the computational speed is much faster than a general-purpose finite element code for the same mesh size. 


\section{Analyses}

The thermal and structural analyses of the front end filter/window assembly for the APS undulator and wiggler have been addressed previously [1 and 3]. The failure criteria for filters and windows were further expanded by Wang and Kuzay [4]. Using these failure criteria, it was concluded that the APS wiggler can operate safely with a 300-micron-thick graphite filter and conventionally built 250 -micron-(10 mil)-thick Be windows. However, operation with the same filter/window assembly can sustain the beam only for undulators with $\mathrm{K}$ values of 1.55 or less. Under these operational conditions, no buckling failure is predicted in the first window due to the thermal stresses or failure in the second window under static atmospheric loading (no sudden shock analysis was considered). The 8.8-mm vertical opening of the window edge is protected by the second fixed mask in the front end, which has a vertical aperture of $6 \mathrm{~mm}$.

In this report, specific emphasis is placed on the filter/window assembly for APS Undulator A operating at $7-\mathrm{GeV}$ storage ring power and $100-\mathrm{mA}$ beam current. The Undulator $\mathrm{A}$ is a $3.3-\mathrm{cm}$ period, 2.4-m long device with a maximum deflection parameter value $\mathrm{K}$ of 2.17 as detailed fully in ANL/APS/TB-3 [5]. The Wiggler A characteristics are those detailed in ANL/APS/TB-11 [6]. However, as opposed to a previous report [1] in which universal windows were considered for either wiggler or undulator operation (at the user's choice), now the focus is on specially configured small-aperture windows strictly applicable for Undulator A operations.

The variables taken into consideration are the gap size of the ID (or the deflection parameter $\mathrm{K})$, the graphite filter thickness, and the Be window thickness. Without loss of generality, the analysis starts with a window and filter $10 \mathrm{~mm} \mathrm{X} 10 \mathrm{~mm}$ in size and edge cooled. Smaller size windows can be considered for undulator beam use only, provided that proper 
upstream aperturing (masking) is designed to protect the window frame from a missteered beam. In the current front end designs, such special fixed masks are not available at this time.

In the analysis, the temperature of the filter and window holding blocks is assumed to be $300^{\circ} \mathrm{K}$. The conductivity of both graphite and $\mathrm{Be}$ is taken to be $2 \mathrm{~W} / \mathrm{cm}^{\circ} \mathrm{K}$ (which is very conservative for graphite). Radiation cooling has been taken into account, and, for conservative reasons, the emissivity of both $\mathrm{Be}$ and graphite is assumed to be 0.2 .

A set of calculations was carried out for window thicknesses of $254 \mu \mathrm{m}, 500 \mu \mathrm{m}, 750 \mu \mathrm{m}$, $1000 \mu \mathrm{m}, 1500 \mu \mathrm{m}$, and $2000 \mu \mathrm{m}$. For each case, the total thickness of the graphite filter was parametrically varied as $0 \mu \mathrm{m}$ (no filter case), $100 \mu \mathrm{m}$, and $200 \mu \mathrm{m}$, respectively.

The analytical results are shown in Figures 2 to 4 . The previous analyses [1] performed on a window of size $10 \mathrm{~mm} \mathrm{X} 80 \mathrm{~mm}$ prove that the difference between the maximum temperature of the beam's footprint and the window boundary can be used as a rule of thumb to judge the structural safety of the window. The allowable maximum temperature difference is about $100^{\circ} \mathrm{K}$. However, this value can be somewhat relaxed if the window is only used for short term (such as for the commissioning period) at the expense of shorter design fatigue life. This relaxation is not allowable for a more permanent window design for which one has to worry about thermally induced fatigue. Also, we assume that the $\mathrm{Be}$ material has a minimum yield stress of $340 \mathrm{MPa}$, a value that is assured from reputable $\mathrm{Be}$ sources, such as Brush Wellman (IF-1, or PS 60 grades).

From the results depicted Figs. 2 through 4 , one can conclude that any curve below the $410^{\circ} \mathrm{K}$ line represents a safe filter/window design. The first number in the notation used in the figures, such as $\mathrm{K}=2.17-100$, is the deflection parameter, and the second is the thickness of 
the graphite filter (in microns). It can be seen in Table 1 that the listed combinations are safe for a $10 \mathrm{~mm}$ X $10 \mathrm{~mm}$ window design, although admittedly the thick window combinations are not practical for most scientific programs due to the excessive photon flux cut off.

With a $200-\mu \mathrm{m}$ graphite filter and a $1.25-\mathrm{mm}$-thick Be window, the window can safely operate with the minimum gap of the device. For the case without a filter, the limit of the deflection parameter for a $1-\mathrm{mm}$ Be window is $\mathrm{K}=1.55$ for safe operation.

The window and filter frames should be designed to handle the absorbed power. This power is about $160 \mathrm{~W}$ for a window in the case of $\mathrm{K}=2.17-200$. The filter frame should withstand a power of $350 \mathrm{~W}$ in this case. For the case $\mathrm{K}=1.55-0$, the window frame should withstand a power of $130 \mathrm{~W}$.

A special-case undulator with a period length of $2.9 \mathrm{~cm}$ and 81 periods has also been considered. Its deflection parameter is $\mathrm{K}=1.865$ when the gap is closed. The distance of the window and filter from the source is 28 meters. Due to the small beam size and slits in the front, the size of the window can be smaller. A set of analyses is performed using XRAP on windows of the following sizes: $10 \mathrm{~mm} \mathrm{X} 8 \mathrm{~mm}, 10 \mathrm{~mm} \mathrm{X} 6 \mathrm{~mm}, 5 \mathrm{~mm} \mathrm{X} 5 \mathrm{~mm}$, and $4 \mathrm{~mm}$ X $4 \mathrm{~mm}$.

It is assumed that the temperature of the filter and the window holding blocks is kept at $300^{\circ} \mathrm{K}$. The thermal conductivity of both the graphite and Be material is $2 \mathrm{~W} / \mathrm{cm}^{\circ} \mathrm{K}$. The radiation effect is taken into account with the emissivity of 0.2 for both $\mathrm{Be}$ and graphite.

For the case of a graphite filter and a $254-\mu \mathrm{m}$ Be window, the results listed in Table 2 show that a Be window of $10 \mathrm{~mm} \mathrm{X} 8 \mathrm{~mm} \mathrm{X} 0.254 \mathrm{~mm}$ or $10 \mathrm{~mm} \mathrm{X} 6 \mathrm{~mm} \mathrm{X} 0.254 \mathrm{~mm}$ can operate safely at a closed gap of $11.5 \mathrm{~mm}$ with a $200-\mu \mathrm{m}$ graphite filter. If a $5 \mathrm{~mm}$ X $5 \mathrm{~mm}$ 
window is used, the window can operate safely without a filter. However, in this case one should be very careful to mask the window frame against any beam damage. The design rule of thumb for the window is to allow at least one-mm total edge protection by the mask. Hence, the upstream cooled mask aperture will be $4 \times 4 \mathrm{~mm}$ for a $5 \times 5 \mathrm{~mm}$ window, which may present considerable manufacturing difficulties. Such masks have not been designed for the APS.

\section{Variable Thickness Windows}

A novel idea that uses a variable thickness window for insertion devices has been proposed [7]. The main advantages of using a variable thickness window are as follows: (1) to make it possible to design a window without filters and therefore make more low-energy photons available to the users; (2) to increase the heat conduction area without increasing the thickness in core area so that the maximum temperature in the window can be significantly decreased; (3) to increase the safety margin of the window system due to the increasing structural integrity, especially with respect to the buckling load in thin windows, which also increases the structural integrity of window against shock due to sudden loss of vacuum; and (4) to increase the window size under the same operating conditions. Compared to a uniform Be window, the variable thickness Be window reduces the likelihood of a catastrophic break.

The window thickness is assumed to take the form of

$$
h(x, y)=a+b x^{2}+c y^{2}+d x y+e x+f y,
$$

where $\mathrm{x}$ is the coordinate in the horizontal direction, and $\mathrm{y}$ is the coordinate in the vertical direction; all the coefficients from a to $\mathrm{f}$ can be freely chosen.

The improved behavior of a window with variable thickness can be seen in Table 3, which compares some selected cases. If one compares two windows that are almost identical except that one is uniform and the other has a variable thickness, one can see that the variable 
thickness window has a significant improvement. For example, comparing two cases, case 16 in Table 3 with $\mathrm{a}=0.254, \mathrm{~b}=\mathrm{c}=0$ (uniform thickness) and case 17 in Table 3 with $\mathrm{a}=$ 0.254 and $b=0.2$ and $c=0.2$, the maximum temperature increment over room temperature for case 16 (uniform thickness) is $415^{\circ} \mathrm{K}$, while that for case 17 is $209^{\circ} \mathrm{K}$, a substantial thermal improvement.

\section{Compton Scattering Effect}

In examining the Compton influence on the calculations on the Be window, calculations were carried out for a $6 \mathrm{~mm} \mathrm{X} 6 \mathrm{~mm} \times 0.254 \mathrm{~mm} \mathrm{Be}$ window with APS Undulator A. The results are listed in Tables 4 and 5 . One can see that the maximum difference between the results that take into consideration Compton scattering and those that do not is only about 6 to 7 percent. Although the ratio of Compton scattering to total absorbed energy increases at high energies, the total net absorption at high energies is very small.

\section{Diamond Windows}

XRAP is used for analysis of diamond windows for both APS Undulator A and Wiggler A. The thermal conductivity used is $12 \mathrm{~W} / \mathrm{cm}^{\circ} \mathrm{K}$, and the window edges are assumed to be clamped and cooled at $300^{\circ} \mathrm{K}$. Different thicknesses have been considered: $10 \mu \mathrm{m}, 50 \mu \mathrm{m}$, $110 \mu \mathrm{m}, 150 \mu \mathrm{m}$, and $200 \mu \mathrm{m}$. Photon transmission calculations from $0.5 \mathrm{keV}$ to $30 \mathrm{keV}$, have also been obtained and are shown in Figures 10 and 11.

The XRAP results are listed in Tables 6 and 7 for Undulator A and Wiggler A, respectively. The same set of results is also plotted in Figs. 5 through 8. The last columns in Tables 6 and 7 show the buckling stresses of the diamond windows. If the maximum thermal stress is larger than the buckling stress, the window will buckle under the thermal load. One can see from Figures 6 and 8 that the thermal stress decreases as the thickness increases because the power absorption per unit thickness decreases when the thickness increases (as shown in Figure 9). However, the buckling stress increases as the thickness increases. Before the two 
curves cross (in Figure 8) the thermal stress is larger than the buckling stress. At a certain diamond thickness (about $150 \mu \mathrm{m}$ ), the curves cross, and, beyond this point, the buckling stress becomes larger than the thermal stress. The point that two curves cross each other is the minimum thickness that can guarantee the structural integrity of the diamond window. Windows with a thickness smaller than this value will buckle. The same trend can be seen in Fig. 6 for Wiggler $\mathrm{A}$.

The buckling behavior of filters and windows has been discussed previously [8], and it is suggested that the post-buckling behavior not be used in the working stage of a window in determining a safe design for a window.

From Fig. 9, one can see that the maximum temperature in a filter is a function of its thickness. The trend exhibits a maximum value. For thin filters, the cooling is dominated by radiative heat transfer, hence the increasing temperature. As the thickness increases, conduction heat transfer dominates reducing the maximum temperature. For both the undulator and the wiggler cases, the maximum temperature is calculated to be no more than $700^{\circ} \mathrm{K}$ for all filter thicknesses larger than $10 \mu \mathrm{m}$.

The special case of a $5 \mathrm{~mm} \mathrm{X} 5 \mathrm{~mm}$ diamond window with a thickness of $100 \mu \mathrm{m}$ is also analyzed. The result reveals that the total absorbed power is about $338 \mathrm{~W}$, and the maximum temperature in the window is $460^{\circ} \mathrm{K}$. The buckling stress is $1386 \mathrm{MPa}$, while the maximum thermal stress is less than $1150 \mathrm{MPa}$. This window can also survive the APS Undulator A radiation without failure.

In conclusion, one can say that the minimum thickness for a safely designed diamond window is 150 microns. Despite all the advantages of the diamond material, such a window (or filter) will cut off $50 \%$ of the photons at energies below $6 \mathrm{keV}$ (see Figure 11). From 
this point of view, beryllium, even at the conventional thicknesses of 250 micron or so, has the distinct advantage over diamond because $50 \%$ of the photons at energies of $3.5 \mathrm{keV}$ and above will pass through.

\section{Oxidation of Beryllium and Sublimation of Graphite}

Non-thermal-stress-type failure phenomena for $\mathrm{Be}$ and graphite involve respectively, oxidization and sublimation. These important issues are briefly discussed below for completeness.

The surface contamination on beryllium has been examined extensively from experimental data and observations at NSLS [9].

Beryllium oxidizes when it comes in contact with air. The Be manufacturer's technical data suggest the following:

When exposed to air, beryllium forms a protective oxide coating, similar to aluminum. The coating protects beryllium when subjected to reentry conditions, which would cause other metals to burn. The oxide film also contributes to beryllium's resistance to damaging oxidation up to $1500 \circ \mathrm{F}[10]$.

The acceptable temperature is $1500^{\circ} \mathrm{F}$ or $816^{\circ} \mathrm{C}$. The data are shown in Figure 12 . According to Hausner [11], beryllium resists oxidation in dry air up to $1100^{\circ} \mathrm{F}$ for long periods of time and to $1500^{\circ} \mathrm{F}$ for short periods without serious effect (Table 8). Oxidation in the form of localized intergranular penetration may begin around $1200^{\circ} \mathrm{F}$ with long time exposures and will increase in severity as the temperature increases. Anodizing treatments provide excellent protection to this type of attack [12]. Table 9 lists the oxidation data of beryllium at elevated temperatures [11].

As for the sublimation of graphite, Reynold's cites the following: 
The vapor pressure becomes equal to 1 atmosphere at $3620^{\circ} \mathrm{K}$. The vapor pressure is complex because the vapor phase includes molecules as well as atoms, but in general the value rises rapidly from a few times $10^{-7} \mathrm{~mm} \mathrm{Hg}$ at $2000^{\circ} \mathrm{C}$ to $6.47 \times 10^{-4} \mathrm{~mm} \mathrm{Hg}$ at $2400^{\circ} \mathrm{C}$ and $1.27 \times 10^{-2} \mathrm{~mm} \mathrm{Hg}$ at $2600^{\circ} \mathrm{C}$ [13].

Mantell [14] gives very similar results that are shown in Table 10 (here) and in Figures 237 and 238 (pp. 372-373, [14]). At a vacuum of $10^{-7} \mathrm{~mm} \mathrm{Hg}$, to avoid sublimation of the graphite material, the maximum temperature should be limited to $2000^{\circ} \mathrm{C}$.

Windowless Operation with the Differential Pump - (Beamline Filter and Window Option) A universal wiggler/undulator-compatible window cannot be designed for the APS front ends due to the combined problems of the large aperture requirement of the wiggler and the high heat flux from the undulator. In addition, some users cannot tolerate windows (no photon losses at low energies) for their scientific programs. Therefore, we have designed a differential pump that is suitable for wiggler/undulator operations at the APS, as shown in Fig. 13. A prototype of this pump has been built and installed on the APS ID front-end mock-up in the high bay of building 362 at the APS. It is currently undergoing gas-loading tests to check out its performance. The plot depicted in Fig. 14 contains limited recent test data from this performance research. Node location 35 on the abscissa indicates the location of the differential pump. Three ion gauges are located on the front-end components (note data symbols in Fig. 14). These are at the exit of the differential pump (node 35), by the front end safety shutter (node 25), and by the first photon shutter (node 8), respectively. The dotted lines in the figure are the vacuum pressure predictions from the vacuum analysis. The symbols correspond to three sets of discrete data with varying gas loading from the exit of the differential pump. The up triangle represents a case of estimated outgassing only, with no bakeout. The others (down triangle and circle) are actual small leak cases. The data suggest that the differential pump is able to maintain over three decades of pressure 
difference at small gas loads. At such small leak rates, the pressure increase in the front end is not felt beyond the safety shutter. Furthermore, these data indicate that agreement with pressure predictions is very good. These tests are continuing so that we can better understand and improve the performance of the APS differential pump. A suitable contamination barrier, like a thin foil to prevent streaming of the contaminants from the beamline side into the front end, is presently under study for the differential pump.

\section{Conclusions and Closing Arguments}

This report provides analyses for a variety of filter and window options for ID beamlines to be used during the commissioning and early phases of operation of the APS. These filters and windows may be temporary; windows may be replaced by differential pumps. Once gradual operational experience and confidence is gained with the differential pump operations, the switch to windowless front ends can be made in a safe manner.

Previously conducted analyses concluded that, with the APS Wiggler A, a 300-micron-thick graphite filter and a conventionally built double Be window will work safely and reliably. Extensive analysis also indicates that the 2.4-meter-long, 3.3-cm-period Undulator A with a maximum $\mathrm{K}$ value of 2.17 will impose unsustainable heat loads on such a window leading to failure unless the beam is filtered excessively or the ID gap is held over $15 \mathrm{~mm}$.

Therefore, the choice was to develop filter and window design options to work specifically with APS Undulator A only during the early phase of the APS operations including commissioning.

Conclusions from the present analyses on such options include the following:

1. A $4 \times 4 \mathrm{~mm}^{2}$ conventional Be window with no filtering can sustain the Undulator $A$ beam with a $\mathrm{K}$ value of 2.17 . Larger size windows without filtering cannot sustain the 
Undulator $A$ beam without failure. The $4 \times 4 \mathrm{~mm}^{2}$ window requires specially designed cooled masks to protect the window frame from damage by the beam.

2. Windows larger than $4 \times 4 \mathrm{~mm}^{2}$ size windows up to $8 \times 8 \mathrm{~mm}^{2}$ will require at least $200-\mu \mathrm{m}$ graphite filtering to sustain the Undulator A beam. These windows also require specially designed cooled masks to protect the window frame from damage by the beam.

3. The variable thickness $\mathrm{Be}$ windows (see Table 2) provide additional options and sizes to work safely with the Undulator A beam, but such windows have not yet been produced. Also, they will require cooled special masks upstream. The variable thickness window is still in the R\&D stage at this time.

4. An $8 \times 8 \mathrm{~mm}^{2} \mathrm{CVD}$ diamond window can sustain the Undulator $\mathrm{A}$ beam provided that it is at least $150 \mu \mathrm{m}$ thick. In addition to the specially designed cooled mask requirement, such a window will cut off photons of energies below $6 \mathrm{keV}$. Hence, the conventionally built Be window may be a better choice. A $5 \times 5 \mathrm{~mm}^{2}$ diamond window $100 \mu \mathrm{m}$ thick is also found to be adequate for the Undulator $A$ beam and it will cut off fewer photons. Diamond windows have not been brazed nor have prototypes be built at the APS at this juncture. Given the brittleness of diamond, one has to be careful in considering this material for windows until sufficient $R \& D$ is in place.

It is highly recommended that all windows be double windows, and a prudent approach to full $100-\mathrm{mA}$ current should be taken. 


\section{Acknowledgment}

Thanks are due to Deming Shu, Chian Liu, Christa Brite, Wen Bing Yun, Thomas Nian, Roger Dejus, and Barry Lai for their input into this report. Thanks are also due to Susan Picologlou for editing the manuscript. 


\section{References}

1. Zhibi Wang, Ulrich Hahn, Roger Dejus, Tuncer M. Kuzay, Thermal and Structural Behavior of Filters and Windows for Synchrotron X-ray Sources, ANL APS LS-217, 1993.

2. Zhibi Wang, X-ray Optical Element Analyses and X-Ray Absorption Package (XRAP). M.Sc Thesis, May 1994, IIT (unpublished). Also in preparation as an APS Light Source Note.

3. Z. B. Wang, U. Hahn, R. Dejus, and T. Kuzay, Filter and Window Behavior for APS Undulator and Wiggler, Presented at the 8th National Conference on Synchrotron Radiation Instrumentation, Aug. 23-26, 1993, Gaithersburg, MD and to appear in Nucl. Instr. Methods in Phy. Res.

4. Z. B. Wang and T Kuzay, Thermo-Mechanical Failure Phenomena in X-ray Windows and Filters and Comparison with Experiments, High Heat Flux Engineering II, Vol. 1997, SPIE- The International Society for Optical Engineering, July 1993.

5. B. Lai, A. Khounsary, R. Savoy, L. Moog, and E. Gluskin, Undulator A Characteristics and Specifications, ANL/APS/TB-3, 1993.

6. B. Lai, A. Khounsary, and E. Gluskin, Wiggler A Characteristics and Specifications, ANL/APS/TB-11, 1993.

7. Zhibi Wang, Tuncer M. Kuzay, A Variable Thickness Window: Thermal and Structural Analyses, to be presented at 1994 SRI International Conference.

8. Z. B. Wang and T. Kuzay, Postbuckling Behavior of Window Subjected to Synchrotron Radiation X-rays. Presented at the 8th National Conference on Synchrotron Radiation Instrumentation, Aug. 23-26, 1993, Gaithersburg, MD and to appear in Nucl. Instr. Methods in Phy. Res.

9. N. F. Gmur, Analysis of Surface Contamination on Beryllium and Aluminum Windows, Nucl. Instrm. Meth. Phys. Res., A266 (1988), 362-374

10. Brush Wellman Inc., Beryllium as a Heat Sink.

11. Ed. H. H. Hausner, The Beryllium Metal Handbook, General Astrometal Co., 1967.

12. Mechanical Properties Data Center, Aerospace Structural Metals Handbook, 1978.

13. W. N. Reynolds, Physical Properties of Graphite, Elsevier Publishing Co. Ltd., 1968.

14. C. L. Mantell, Carbon and Graphite Handbook Interscience Publishers, New York, 1968. 
Table 1. Insertion Device Deflection Parameter, $\mathrm{K}$, versus the Temperatures on the Filter and Beryllium Window for Various Filter/Window Thicknesses

\begin{tabular}{lccc}
\hline Case & $\begin{array}{c}\text { Minimum Thickness } \\
\text { of Window }\end{array}$ & $\begin{array}{c}\text { Maximum Temperature } \\
\text { Difference on Window }\end{array}$ & $\begin{array}{c}\text { Maximum } \\
\text { Temperature for Filter }\end{array}$ \\
\hline $\mathrm{K}=1.55-200^{*}$ & $(\mu \mathrm{m})$ & $\left({ }^{\circ} \mathrm{K}\right)$ & $\left({ }^{\mathrm{K}}\right)$ \\
$\mathrm{K}=1.55-100$ & 254 & 90 & 850 \\
$\mathrm{~K}=1.55-0$ & 254 & 104 & 900 \\
$\mathrm{~K}=1.71-200$ & 1000 & 110 & $\mathrm{~N} / \mathrm{A}$ \\
$\mathrm{K}=1.88-200$ & 750 & 110 & 1120 \\
$\mathrm{~K}=2.17-200$ & 1200 & 110 & 1330 \\
\hline
\end{tabular}

* The first number in the notation used is the deflection parameter, $\mathrm{K}$, and the second is the thickness of the graphite filter (in microns).

Table 2. Selected Results from the Window Analysis of a Special Undulator A (2.9-cm Period, 81 Total Periods, and $\mathrm{K}=1.865$ ). Window is at $28 \mathrm{~m}$ from source.

\begin{tabular}{|c|c|c|c|c|c|c|}
\hline Case & $\begin{array}{c}\text { Filter } \\
\text { Thickness } \\
\text { (um) }\end{array}$ & $\begin{array}{l}\text { Window } \\
\text { Thickness } \\
\text { (um) }\end{array}$ & $\begin{array}{c}\text { Absorbed } \\
\text { Power in } \\
\text { Filter } \\
\text { (W) }\end{array}$ & $\begin{array}{l}\text { Absorbed } \\
\text { Power in } \\
\text { Window } \\
\text { (W) }\end{array}$ & $\begin{array}{c}T_{\max } \text { in } \\
\text { Filter } \\
\left({ }^{\circ} \mathrm{K}\right)\end{array}$ & $\begin{array}{c}\mathrm{T}_{\max } \text { in } \\
\text { Window } \\
\left({ }^{\circ} \mathrm{K}\right)\end{array}$ \\
\hline $10 \times 8 \mathrm{~mm}^{2}$ & 300 & 254 & 278 & 26.1 & 1018 & 385 \\
\hline $10 \times 8 \mathrm{~mm}^{2}$ & 200 & 254 & 217 & 32.9 & 1123 & 407 \\
\hline $10 \times 6 \mathrm{~mm}^{2}$ & 300 & 254 & 278 & 26.1 & 1018 & 367 \\
\hline $10 \times 6 \mathrm{~mm}^{2}$ & 200 & 254 & 217 & 32.9 & 1123 & 383 \\
\hline $10 \times 6 \mathrm{~mm}^{2}$ & 100 & 254 & 134 & 45.3 & 1270 & 442 \\
\hline $10 \times 6 \mathrm{~mm}^{2}$ & 0 & 254 & & 75 & & 510 \\
\hline $5 \times 5 \mathrm{~mm}^{2}$ & 0 & 254 & & 75 & & 400 \\
\hline $4 \times 4 \mathrm{~mm}^{2}$ & 0 & 254 & & 75 & & 366 \\
\hline
\end{tabular}


Table 3. Absorbed Power and Maximum Temperature Difference at Filter and Window for the APS Undulator A

\begin{tabular}{|c|c|c|c|c|c|c|c|c|c|c|}
\hline \multirow{2}{*}{ Case } & \multirow{2}{*}{$\begin{array}{c}\text { Size of } \\
\text { Window }\end{array}$} & \multirow{2}{*}{$\begin{array}{c}\text { Filter } \\
\text { Thick- } \\
\text { ness } \\
(\mu \mathrm{m})\end{array}$} & \multicolumn{3}{|c|}{$\begin{array}{l}\text { Window Thickness } \\
\text { Parameters* }\end{array}$} & \multirow{2}{*}{$\begin{array}{l}\text { Absorbed } \\
\text { Power in } \\
\text { Filter } \\
\text { (W) }\end{array}$} & \multirow{2}{*}{$\begin{array}{l}\text { Absorbed } \\
\text { Power in } \\
\text { Window } \\
\text { (W) }\end{array}$} & \multirow{2}{*}{$\begin{array}{l}\text { Max } \\
\text { Temp. of } \\
\text { Filter } \\
\text { (OK) }\end{array}$} & \multirow{2}{*}{$\begin{array}{c}\text { Max } \\
\text { Temp. of } \\
\text { Window } \\
\left({ }^{\circ}\right)\end{array}$} & \multirow[t]{2}{*}{ Safe } \\
\hline & & & a & b & c & & & & & \\
\hline 1 & $4 \times 4$ & 0 & 0.254 & 0.0 & 0.0 & N/A & 161.9 & N/A & 413.0 & Yes \\
\hline 2 & $5 \times 5$ & 0 & 0.150 & 0.2 & 0.2 & NA & 299.0 & N/A & 400.0 & Yes \\
\hline 3 & $5 \times 5$ & 0 & 0.254 & 0.2 & 0.2 & NA & 311.0 & N/A & 407.6 & Yes \\
\hline 4 & $6 \times 6$ & 0 & 0.125 & 0.2 & 0.2 & N/A & 269.5 & N/A & 425.9 & No \\
\hline 5 & $6 \times 6$ & 0 & 0.125 & 0.2 & 0.4 & NA & 3.15 .6 & N/A & 408.3 & Yes \\
\hline 6 & $6 \times 6$ & 0 & 0.125 & 0.1 & 0.2 & NA & 239.1 & N/A & 438.7 & No \\
\hline 7 & $6 \times 6$ & 0 & 0.125 & 0.2 & 0.0 & N/A & 197.0 & N/A & 449.0 & No \\
\hline 8 & $6 \times 6$ & 0 & 0.254 & 0.1 & 0.1 & N/A & 250.6 & N/A & 464.0 & No \\
\hline 9 & $6 \times 6$ & 0 & 0.254 & 0.0 & 0.0 & N/A & 163.4 & N/A & 528.0 & No \\
\hline 10 & $7 \times 7$ & 0 & 0.125 & 0.2 & 0.4 & N/A & 315.6 & N/A & 429.6 & No \\
\hline 11 & $7 \times 7$ & 0 & 0.100 & 0.2 & 0.4 & NA & 310.4 & N/A & 428.6 & No \\
\hline 12 & $7 \times 7$ & 0 & 0.100 & 0.4 & 0.4 & N/A & 355.9 & N/A & 415.0 & Yes \\
\hline 13 & $8 \times 8$ & 0 & 0.254 & 0.2 & 0.2 & NA & 311.0 & N/A & 488.8 & No \\
\hline 14 & $8 \times 8$ & 200 & 0.254 & 0.2 & 0.2 & 355.5 & 112.9 & 1396.0 & 369.7 & Yes \\
\hline 15 & $8 \times 8$ & 200 & 0.254 & 0.0 & 0.0 & 355.5 & 40.4 & 1396.0 & 405.5 & Yes \\
\hline 16 & $9 \times 9$ & 0 & 0.254 & 0.0 & 0.0 & NA & 163.4 & N/A & 715.0 & No \\
\hline 17 & $9 \times 9$ & 0 & 0.254 & 0.2 & 0.2 & N/A & 311.0 & N/A & 509.0 & No \\
\hline 18 & $9 \times 9$ & 200 & 0.254 & 0.2 & 0.2 & 355.5 & 112.9 & 1396.0 & 377.1 & Yes \\
\hline 19 & $10 \times 10$ & 200 & 0.254 & 0.2 & 0.2 & 355.5 & 112.9 & 1396.0 & 382.2 & Yes \\
\hline
\end{tabular}

*Window thickness is defined by:

$$
h(x, y)=a+b x^{2}+c y^{2}
$$


Table 4. Effect of Compton Scattering on the Window Analysis

\begin{tabular}{ccrrrr}
\hline Case & $\begin{array}{c}\text { Compton } \\
\text { Part }\end{array}$ & $\begin{array}{c}E_{\min } \\
(\mathrm{keV})\end{array}$ & $\begin{array}{c}E_{\max } \\
(\mathrm{keV})\end{array}$ & $\begin{array}{c}\text { Absorbed Power } \\
(\mathrm{W})\end{array}$ & Max Temperature \\
\hline 1 & 0 & .6 & 30 & 150.5 & 503.8 \\
2 & 1 & .6 & 30 & 159.8 & 519.7 \\
3 & 0 & .6 & 60 & 150.9 & 504.5 \\
4 & 1 & .6 & 60 & 160.7 & 521.6 \\
\hline
\end{tabular}

Table 5. Ratio of Compton Scattering to Total Energy Absorbed at Different Energy Bandwidths

\begin{tabular}{cccc}
\hline Energy range & $\begin{array}{c}\text { From } 0.6 \text { to } 30 \\
\mathrm{keV}\end{array}$ & $\begin{array}{c}\text { From } 0.6 \text { to } 60 \\
\mathrm{keV}\end{array}$ & $\begin{array}{c}\text { From } 30 \text { to } 60 \\
\mathrm{keV}\end{array}$ \\
\hline E2/E1* & $6.2 \%$ & $6.5 \%$ & $125 \%$ \\
\hline
\end{tabular}

* E1 is the total absorbed energy with no Compton scattering

E2 is the absorbed energy only due to Compton scattering 
Table 6. Analytical Results for an $8 \mathrm{~mm} \mathrm{X} 8 \mathrm{~mm}$ Diamond Window for the APS Undulator A

\begin{tabular}{ccccccr}
\hline $\begin{array}{c}\text { Thickness } \\
\text { (micron) }\end{array}$ & $\begin{array}{c}\text { Absorbed } \\
\text { Power } \\
(\mathrm{W})\end{array}$ & $\begin{array}{c}\mathrm{T}_{\max } \\
\left({ }^{\circ} \mathrm{K}\right)\end{array}$ & $\begin{array}{c}\text { Maximum } \\
\sigma_{\mathrm{x}}(\mathrm{MPa})\end{array}$ & $\begin{array}{c}\text { Maximum } \\
\sigma_{\mathrm{y}}(\mathrm{MPa})\end{array}$ & $\begin{array}{c}\text { Maximum } \\
\sigma(\mathrm{MPa})\end{array}$ & $\begin{array}{c}\text { Buckling } \\
\text { Stress } \\
(\mathrm{MPa})\end{array}$ \\
\hline 10 & 75 & 870 & 2256 & 2218 & 2392 & 5 \\
50 & 222 & 701 & 1584 & 1694 & 1639 & 123 \\
110 & 338 & 592 & 1162 & 1208 & 1183 & 595 \\
150 & 392 & 551 & 1003 & 1032 & 1016 & 1107 \\
200 & 448 & 516 & 868 & 883 & 874 & 1969 \\
\hline
\end{tabular}

Table 7. Analytical Results for a $75 \mathrm{~mm} \mathrm{X} 15 \mathrm{~mm}$ Diamond Window for the APS Wiggler A

\begin{tabular}{ccccccc}
\hline $\begin{array}{c}\text { Thickness } \\
\text { (micron) }\end{array}$ & $\begin{array}{c}\text { Absorbed } \\
\text { Power } \\
(\mathrm{W})\end{array}$ & $\begin{array}{c}\mathrm{T}_{\max } \\
\left({ }^{\circ} \mathrm{K}\right)\end{array}$ & $\begin{array}{c}\text { Maximum } \\
\sigma_{\mathrm{x}}(\mathrm{MPa})\end{array}$ & $\begin{array}{c}\text { Maximum } \\
\sigma_{\mathrm{y}}(\mathrm{MPa})\end{array}$ & $\begin{array}{c}\text { Maximum } \\
\sigma(\mathrm{MPa})\end{array}$ & $\begin{array}{c}\text { Buckling } \\
\text { Stress } \\
(\mathrm{MPa})\end{array}$ \\
\hline 10 & 167 & 1007 & 3567 & 2577 & 3148 & 2 \\
50 & 211 & 487 & 1007 & 692 & 884 & 39 \\
110 & 268 & 411 & 610 & 407 & 536 & 186 \\
150 & 301 & 393 & 518 & 343 & 456 & 347 \\
200 & 345 & 381 & 452 & 298 & 398 & 616 \\
\hline
\end{tabular}


Table 8. Oxidation Of Beryllium in Air at Elevated Temperatures [adapted from 11]

\begin{tabular}{|c|c|c|}
\hline Source & \multicolumn{2}{|l|}{ (19) } \\
\hline Alloy & \multicolumn{2}{|c|}{$\mathrm{Be}$} \\
\hline Form & \multicolumn{2}{|c|}{ Extruded Rod and Hot Pressed Block } \\
\hline $\begin{array}{l}\text { Temp. } \\
\left({ }^{\circ} \mathrm{F}\right)\end{array}$ & Appearance after 1 Hour & \begin{tabular}{|c} 
Time to Produce \\
Noticeable \\
Corrosion - Hours
\end{tabular} \\
\hline $\begin{array}{l}1292 \\
1472 \\
1652 \\
1832\end{array}$ & $\begin{array}{l}\text { Barely perceptible temper film } \\
\text { White film } \\
\text { White film } \\
\text { Heavy white scale }\end{array}$ & $\begin{array}{r}60 \\
12 \\
1 \\
--\end{array}$ \\
\hline
\end{tabular}


Table 9. Oxidation of Beryllium at Elevation Temperature* [adapted from 11]

Temperature, ${ }^{\circ} \mathrm{C}$

untreated $\stackrel{705}{\text { anodized untreated }} \stackrel{807}{ }$ anodized_untreated $\stackrel{1030}{\text { anodized }}$

\begin{tabular}{|l|c|c|c|c|c|c|}
\hline 10 & 0 & 0.08 & 1 & 0.2 & 4 & 0.35 \\
\hline 20 & 0 & 0.1 & 7 & 0.25 & 13 & 0.45 \\
\hline 30 & 1 & 0.1 & 20 & 0.3 & 30 & 0.48 \\
\hline 40 & 1 & 0.1 & 35 & 0.3 & n.m. & 0.52 \\
\hline 50 & 3 & 0.1 & $>60$ & 0.3 & n.m. & 0.55 \\
\hline 60 & 7 & 0.1 & n.m. & 0.3 & n.m. & 0.60 \\
\hline
\end{tabular}

*Expressed as weight gain in $\mathrm{mg} / \mathrm{cm}^{2}$ 
Table 10. Vapor Pressure of Graphite [adapted from 14]

Vapor Pressure

\begin{tabular}{|c|c|c|c|c|c|c|c|c|}
\hline \multicolumn{3}{|c|}{ Temperature } & \multicolumn{4}{|c|}{ Partial pressures of species in atmospheres } & \multirow{2}{*}{$\begin{array}{l}\text { Equivalent vapor } \\
\text { pressure }(\mathrm{atm})^{1}\end{array}$} & \multirow{2}{*}{$\begin{array}{l}\text { Eree Vaporization } \\
\text { rate }\left(\mathrm{g} / \mathrm{cm}^{2} \mathrm{sec}\right)\end{array}$} \\
\hline${ }^{\circ} \mathrm{K}$ & ${ }^{\circ} \mathrm{C}$ & $\mathrm{C}$ & $\mathrm{C}_{2}$ & $\mathrm{C}_{3}$ & $\overline{\mathrm{C}_{4}}$ & $\mathrm{C}_{5}$ & & \\
\hline 1200 & 927 & $1.01 \times 10^{-23}$ & & & & & $1.17 \times 10^{-23}$ & $5.19 \times 10^{-23}$ \\
\hline 1300 & 1027 & $2.81 \times 10^{-21}$ & & $2.38 \times 10^{-22}$ & & & $3.54 \times 10^{-21}$ & $1.51 \times 10^{-20}$ \\
\hline 1400 & 1127 & $3.21 \times 10^{-19}$ & $1.015 \times 10^{-21}$ & $4.37 \times 10^{-20}$ & & & $4.54 \times 10^{-19}$ & $1.87 \times 10^{-18}$ \\
\hline 1500 & 1227 & $1.95 \times 10^{-17}$ & $1.34 \times 10^{-19}$ & $3.96 \times 10^{-18}$ & & & $3.16 \times 10^{-17}$ & $1.26 \times 10^{-16}$ \\
\hline 1600 & 1327 & $7.08 \times 10^{-16}$ & $8.55 \times 10^{-18}$ & $2.04 \times 10^{-16}$ & & & $1.34 \times 10^{-15}$ & $5.15 \times 10^{-15}$ \\
\hline 1700 & 1427 & $1.68 \times 10^{-14}$ & $3.34 \times 10^{-16}$ & $6.55 \times 10^{-15}$ & $3.11 \times 10^{-20}$ & $4.47 \times 10^{-20}$ & $3.72 \times 10^{-14}$ & $1.39 \times 10^{-13}$ \\
\hline 1800 & 1527 & $2.81 \times 10^{-13}$ & $8.65 \times 10^{-15}$ & $1.42 \times 10^{-13}$ & $1.62 \times 10^{-18}$ & $2.33 \times 10^{-18}$ & $7.25 \times 10^{-13}$ & $2.64 \times 10^{-12}$ \\
\hline 1900 & 1627 & $3.47 \times 10^{-12}$ & $1.59 \times 10^{-13}$ & $2.45 \times 10^{-12}$ & $5.52 \times 10^{-17}$ & $8.00 \times 10^{-17}$ & $1.08 \times 10^{-11}$ & $3.81 \times 10^{-11}$ \\
\hline 2000 & 1727 & $3.34 \times 10^{-11}$ & $2.21 \times 10^{-12}$ & $3.10 \times 10^{-11}$ & $1.03 \times 10^{-15}$ & $1.92 \times 10^{-15}$ & $1.31 \times 10^{-10}$ & $4.61 \times 10^{-10}$ \\
\hline 2500 & 2227 & $1.79 \times 10^{-7}$ & $4.30 \times 10^{-8}$ & $2.62 \times 10^{-7}$ & $2.15 \times 10^{-10}$ & $3.17 \times 10^{-10}$ & $1.05 \times 10^{-6}$ & $3.23 \times 10^{-6}$ \\
\hline 3000 & 2727 & $5.43 \times 10^{-5}$ & $3.03 \times 10^{-5}$ & $1.41 \times 10^{-4}$ & $6.05 \times 10^{-7}$ & $8.97 \times 10^{-7}$ & $5.38 \times 10^{-4}$ & $1.51 \times 10^{-3}$ \\
\hline 3500 & 3227 & $3.18 \times 10^{-3}$ & $1.38 \times 10^{-3}$ & $3.20 \times 10^{-2}$ & $1.68 \times 10^{-4}$ & $2.49 \times 10^{4}$ & $5.30 \times 10^{-2}$ & 0.138 \\
\hline 4000 & 3727 & $6.67 \times 10^{-2}$ & 0.103 & 0.47 & $1.10 \times 10^{-2}$ & $1.64 \times 10^{-2}$ & 1.83 & 5.29 \\
\hline 4500 & 4227 & 0.708 & 1.52 & 7.13 & 0.276 & 0.408 & 28.3 & 65.0 \\
\hline 5000 & 4727 & 4.66 & 12.9 & 72.5 & 3.54 & 5.20 & 288 & 627 \\
\hline 5500 & 5227 & 21.6 & 72.8 & 839 & 27.8 & 40.6 & 3000 & 6240 \\
\hline 6000 & 5727 & 77.6 & 307 & 6390 & 152 & 220 & 21600 & 43000 \\
\hline
\end{tabular}

The equivalent pressure is the pressure that would be observed if the vapor were monoatomic carbon 


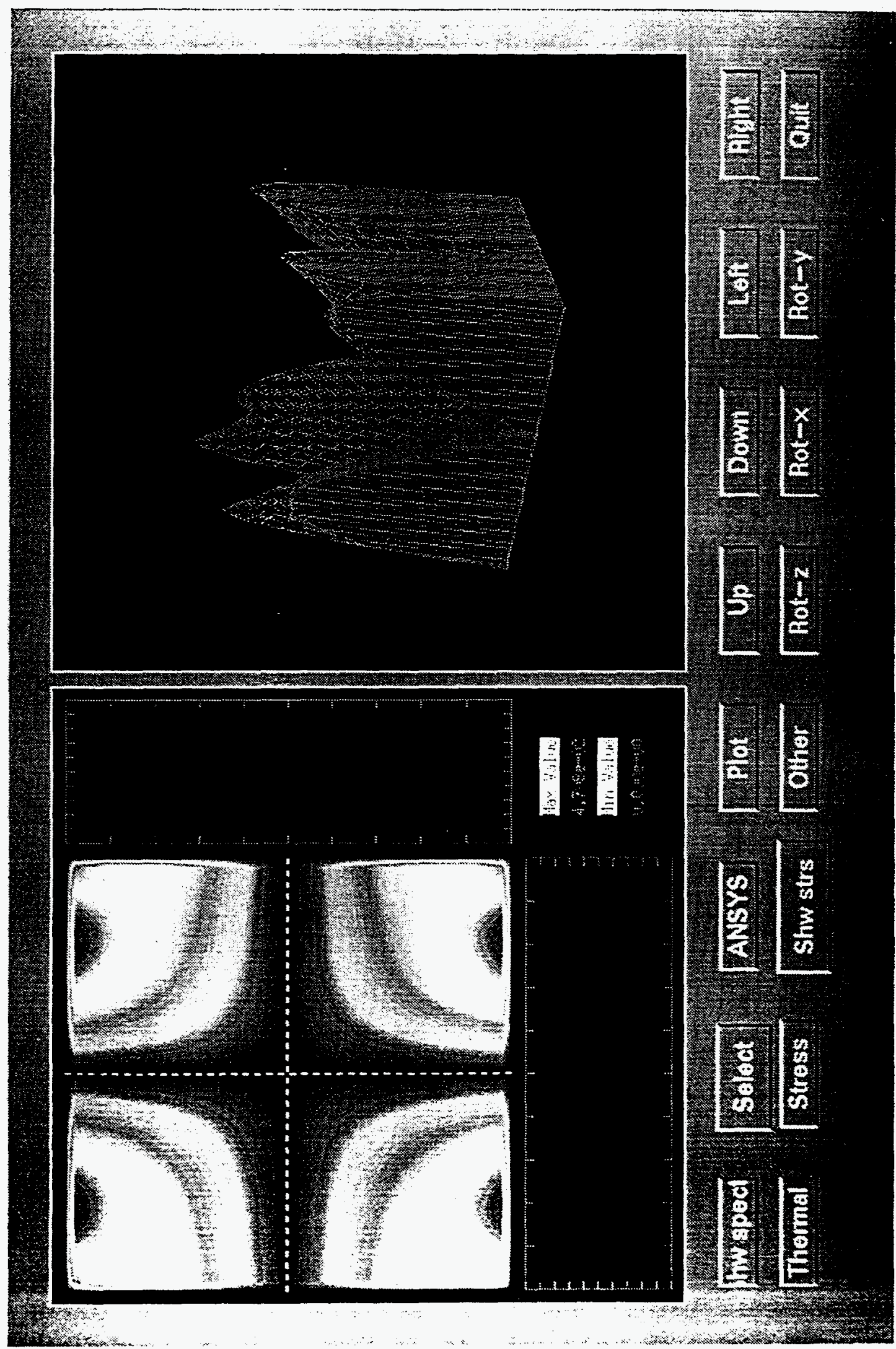

兽 


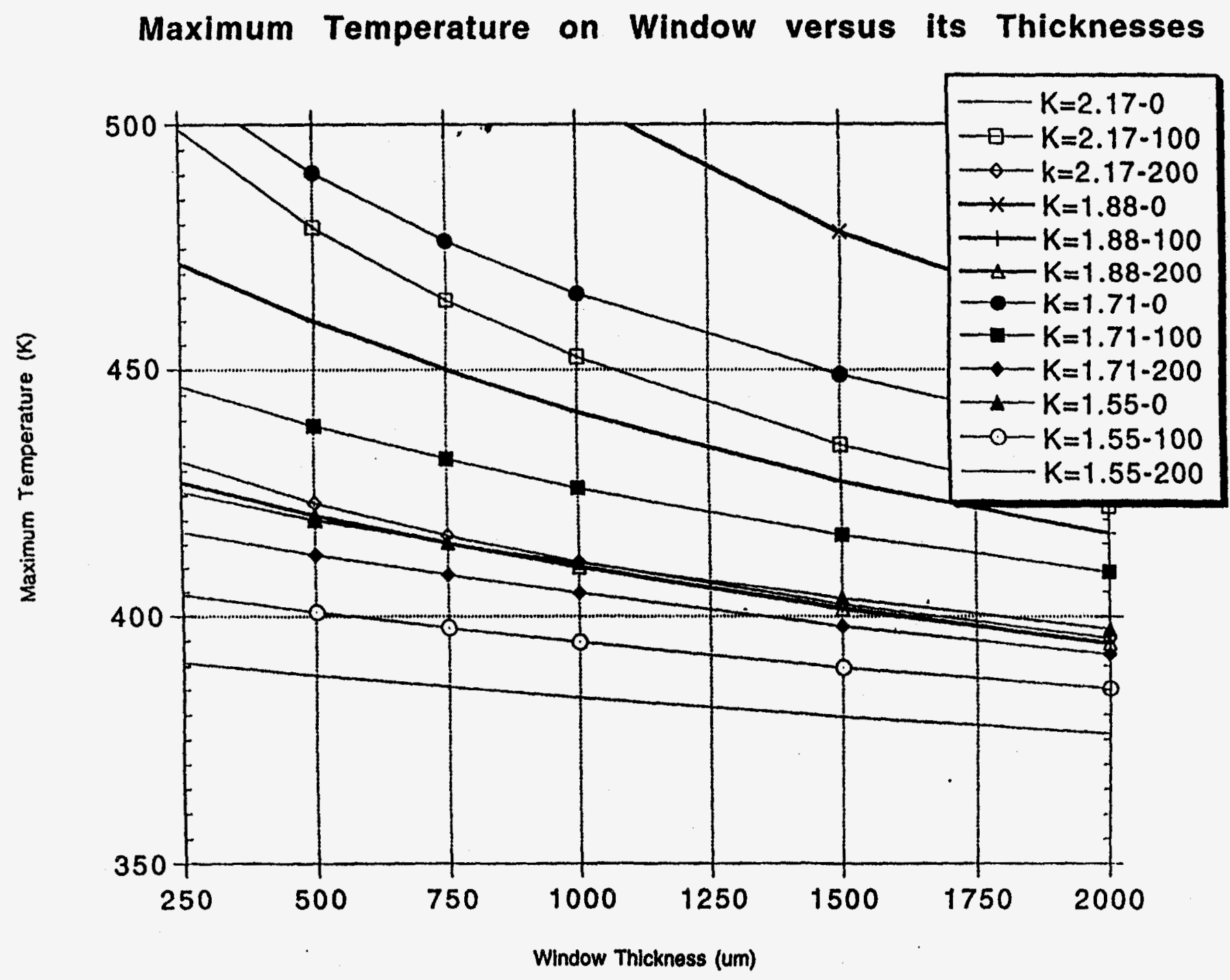

Figure 2. The Maximum Temperature of Windows at Different Gaps 


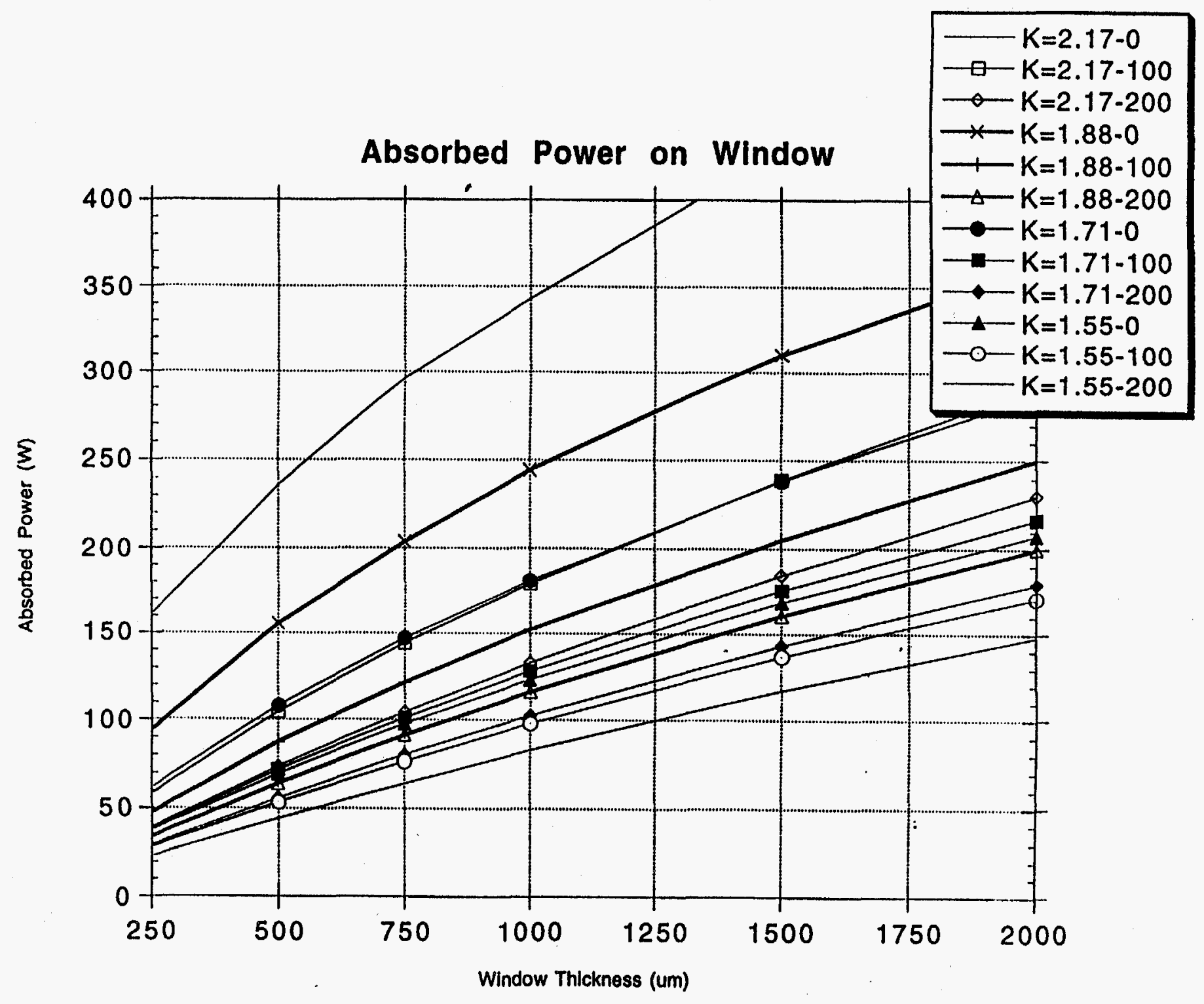

Figure 3. Absorbed Power of Windows at Different Gaps 


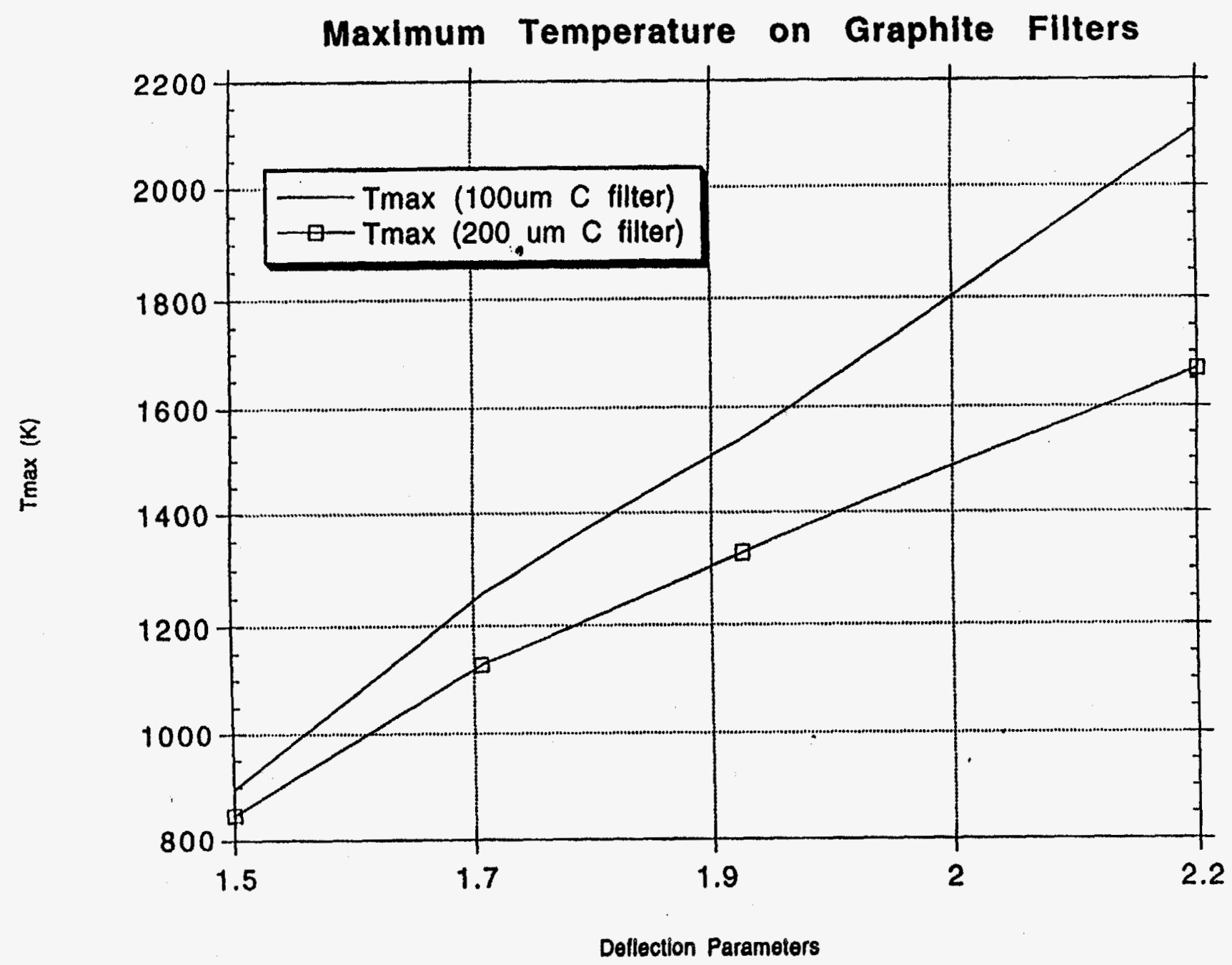

Figure 4. The Maximum Temperature on Graphite Filters 


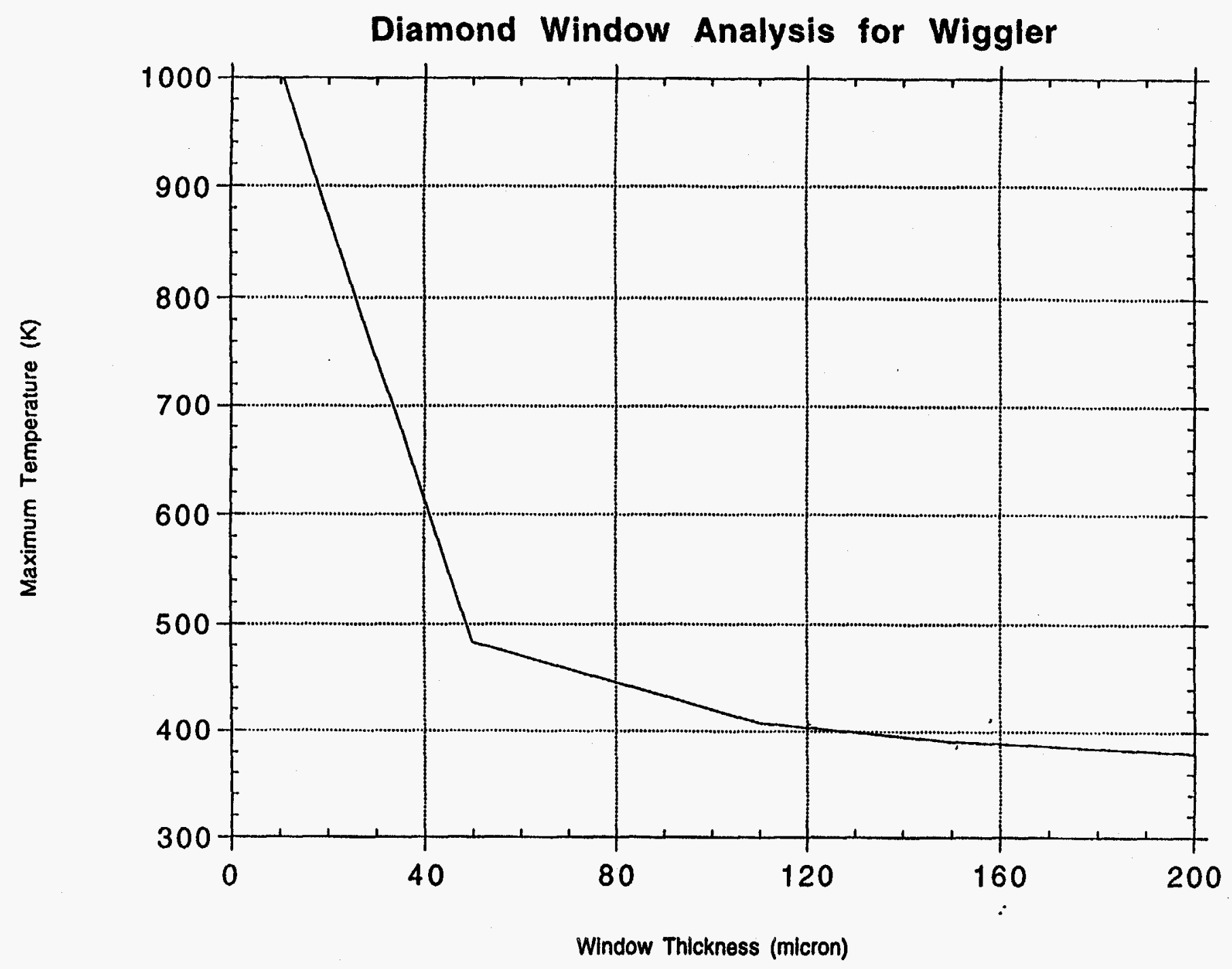

Figure 5. The Maximum Temperature in Window of APS Wiggler 


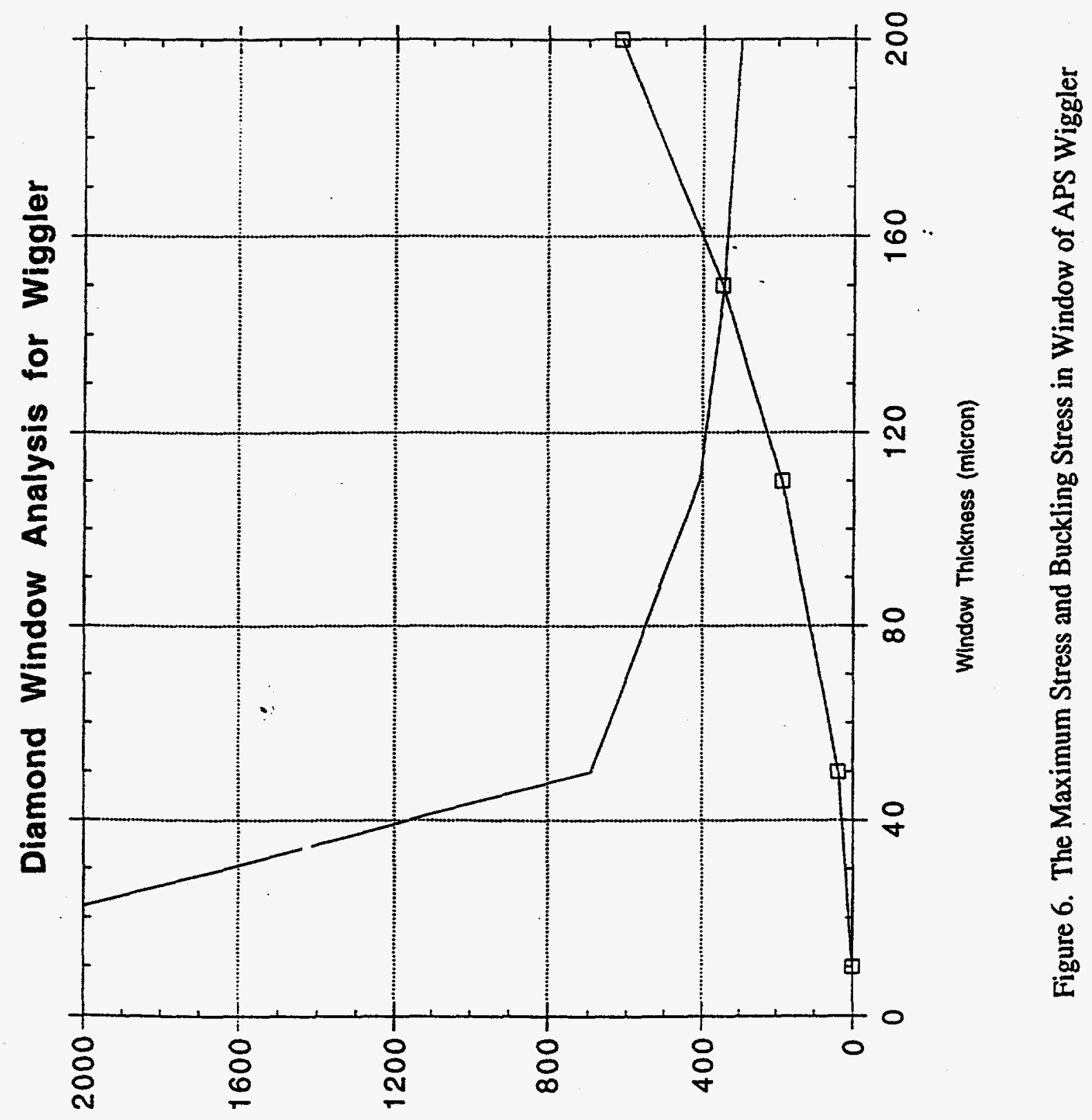

(edW) ssans 


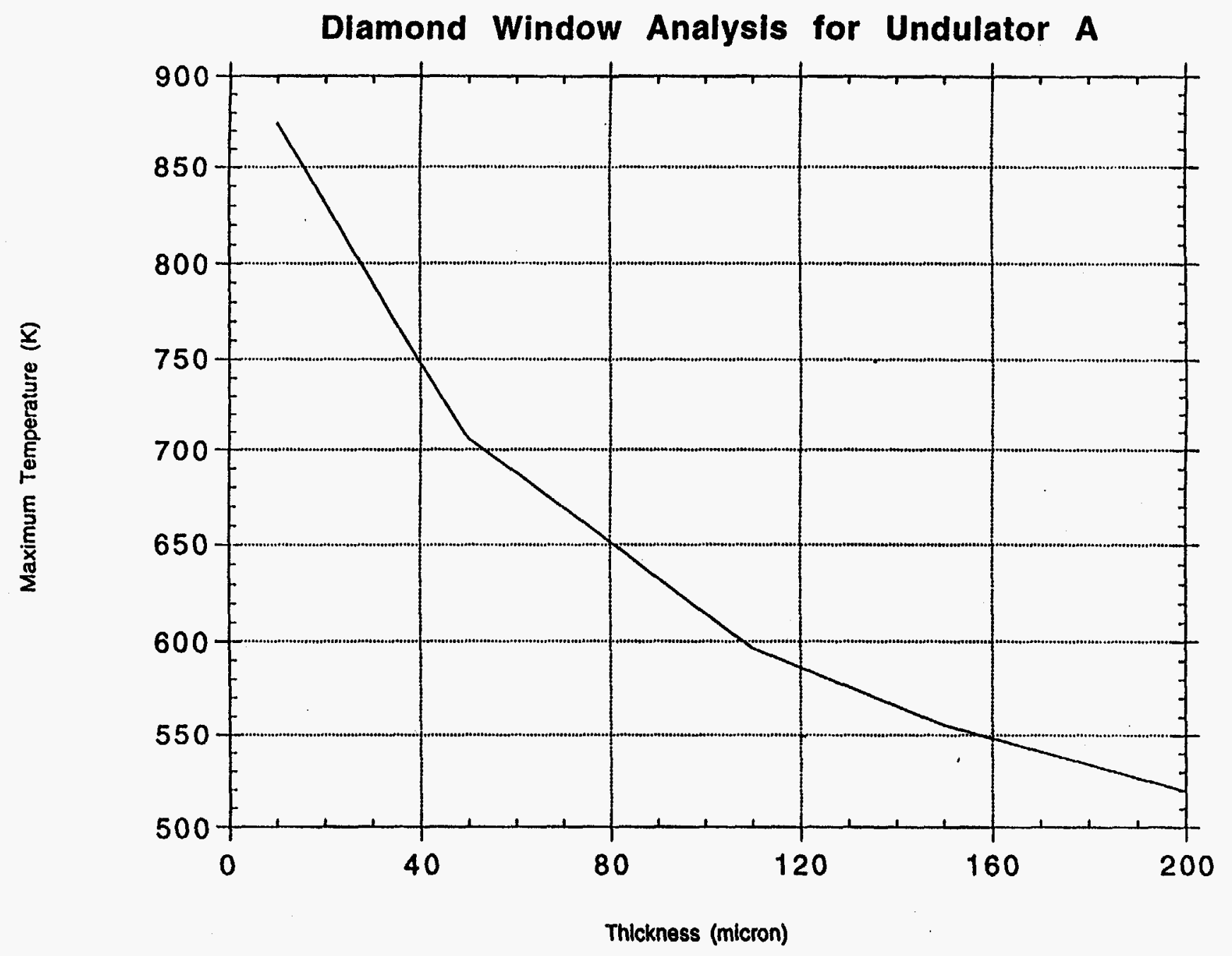

Figure 7. The Maximum Temperature in Window of APS Undulator 


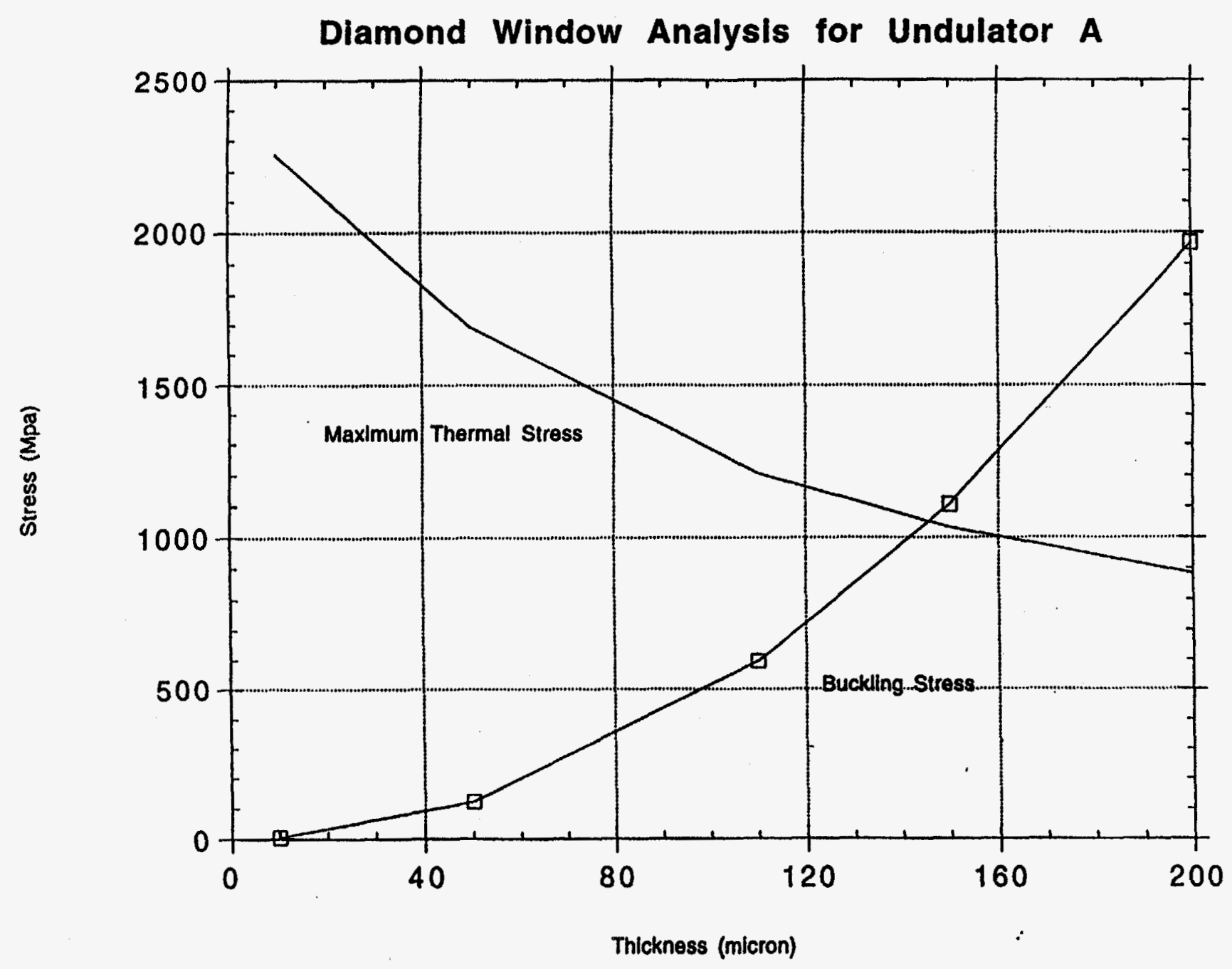

Figure 8. The Maximum Stress and Buckling Stress in Window of APS Undulator 
Absorbed Power and Maximum Temperature in the Filter for APS Undulator A

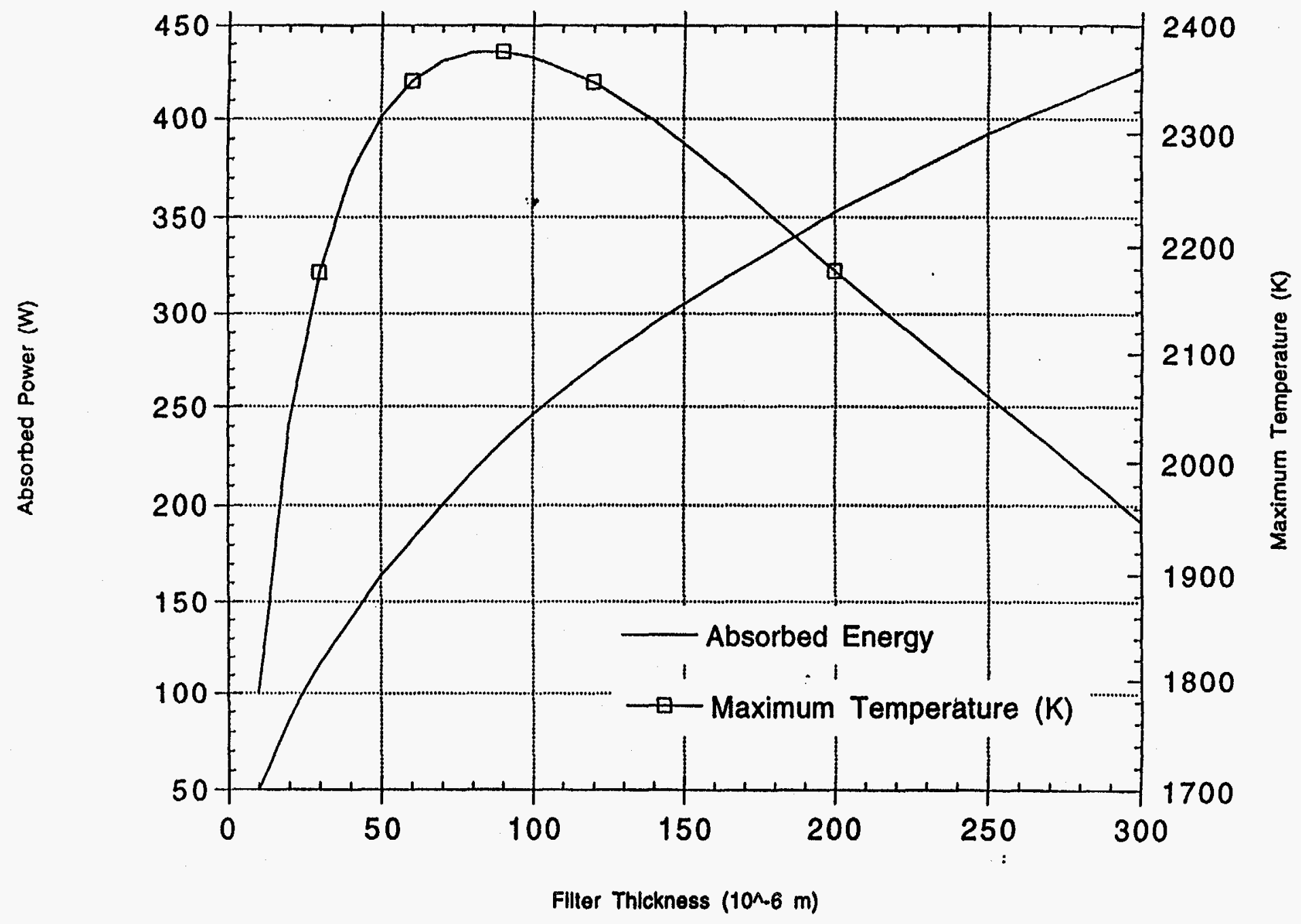

Figure 9. Absorbed Power and Maximum Temperature in Filter for APS Undulator 
Photon Transmission Through 10, 30, 50, 70, 100, 150, 200, 250, 300, 500, And 1000 Micron Be Filters

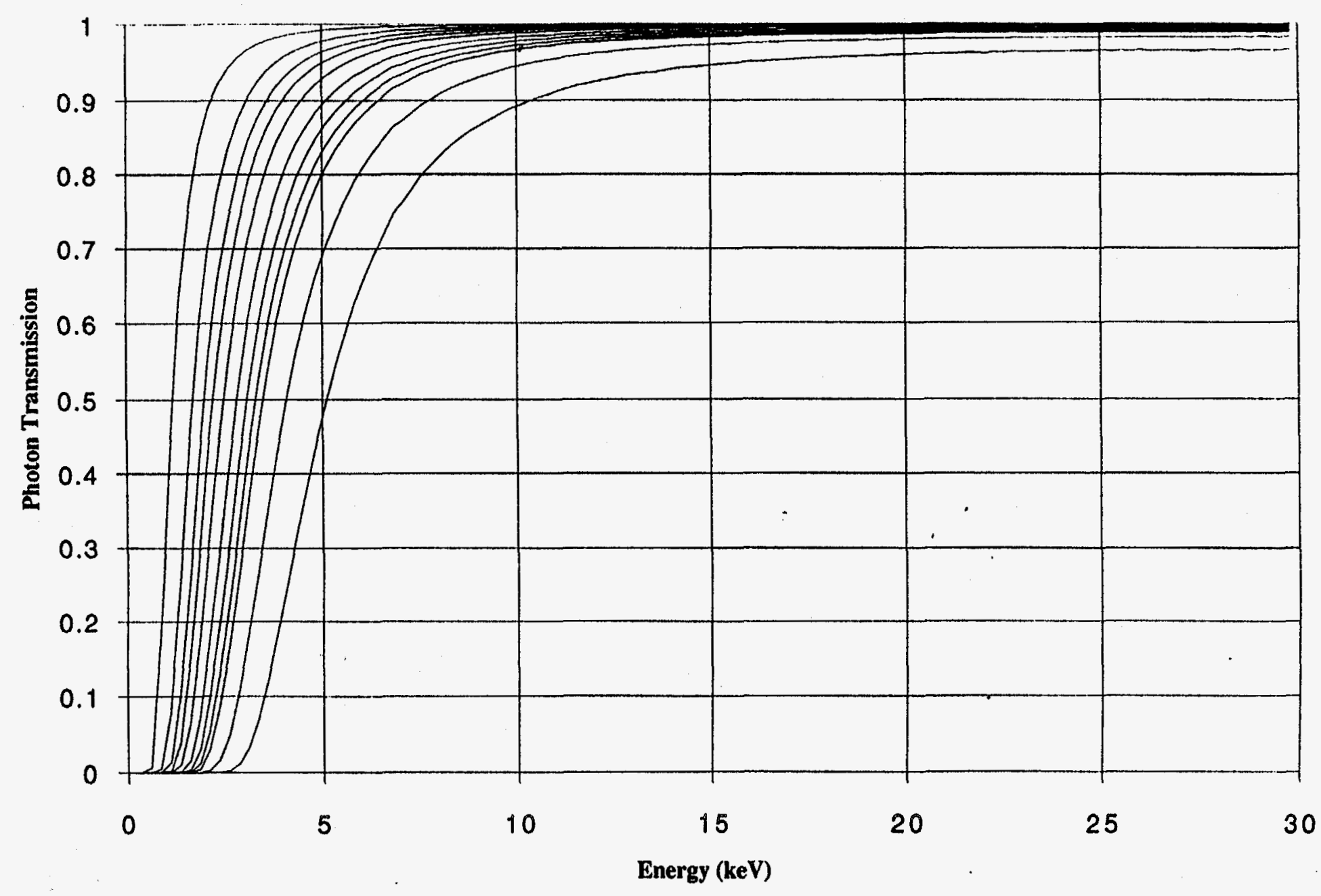

Figure 10. Photon Transmission Through a Beryllium Window/Filter as a function of Energy 
Photon Transmission Through 10, 30, 50, 70, 100, 150, 200, 250, 300, 500, And 1000 Micron Be Filters

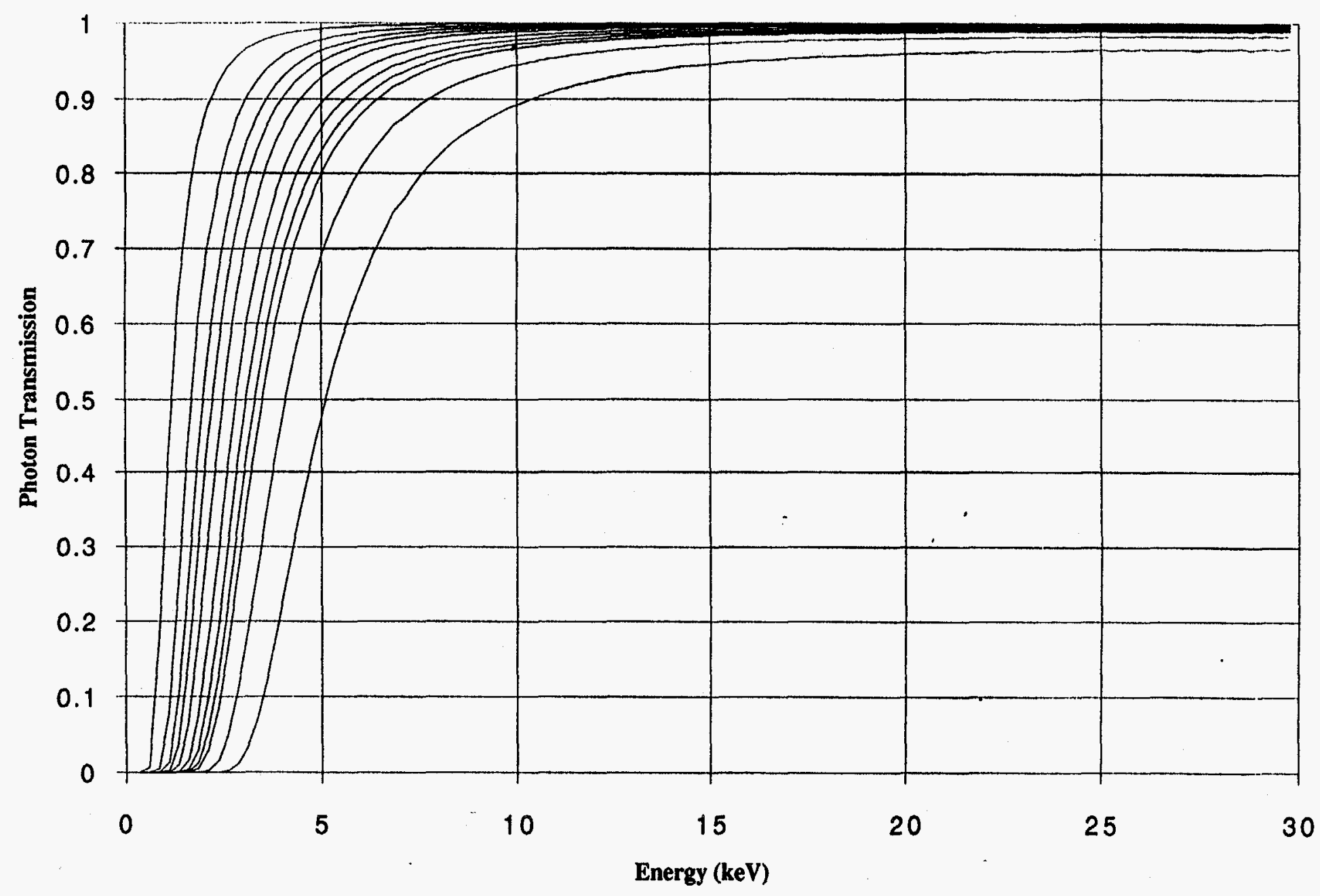
Figure 11. Photon Transmission Through a Diamond Window/Filter as a function of
Energy 


\section{OXIDATION RESISTANCE}

When exposed to air, beryllium forms a protective oxide coating, similar to aluminum. The coating protects beryllium when subjected to re-entry conditions, which would cause other metals to burn. The oxide film also contributes to beryllium's resistance to damaging oxidation up to $1500^{\circ} \mathrm{F}$.

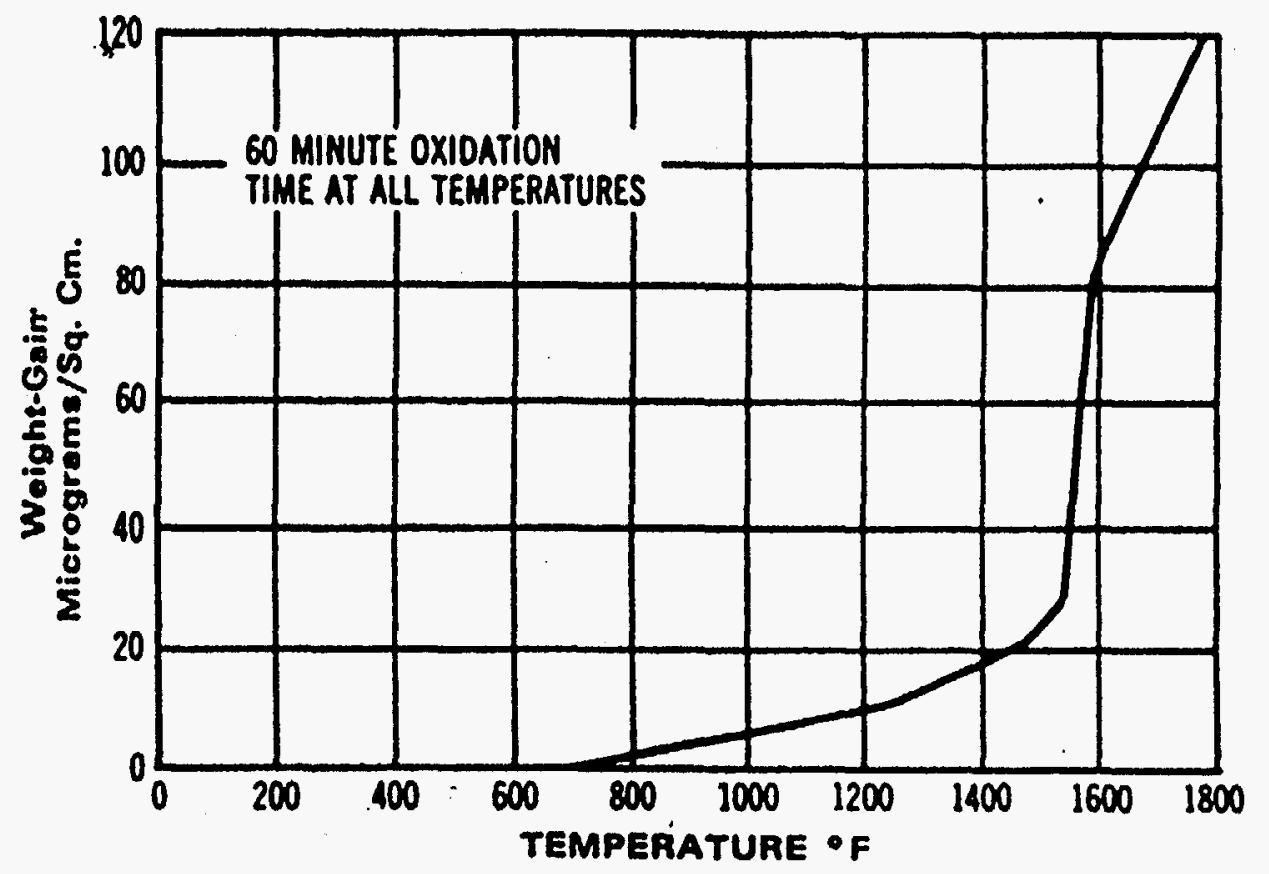

Figure 12. Oxidation Resistance of Beryllium at Different Temperatures

(Reprinted with permission from "Beryllium as a Heat Sink," Brush Wellman Inc. [10]. Note that this graph originates from the book, The Metal Beryllium, by D. W. White, Jr., and J. E. Burke, ASM, 1955. It was reproduced in the Brush Wellman report with some very minor changes.) 


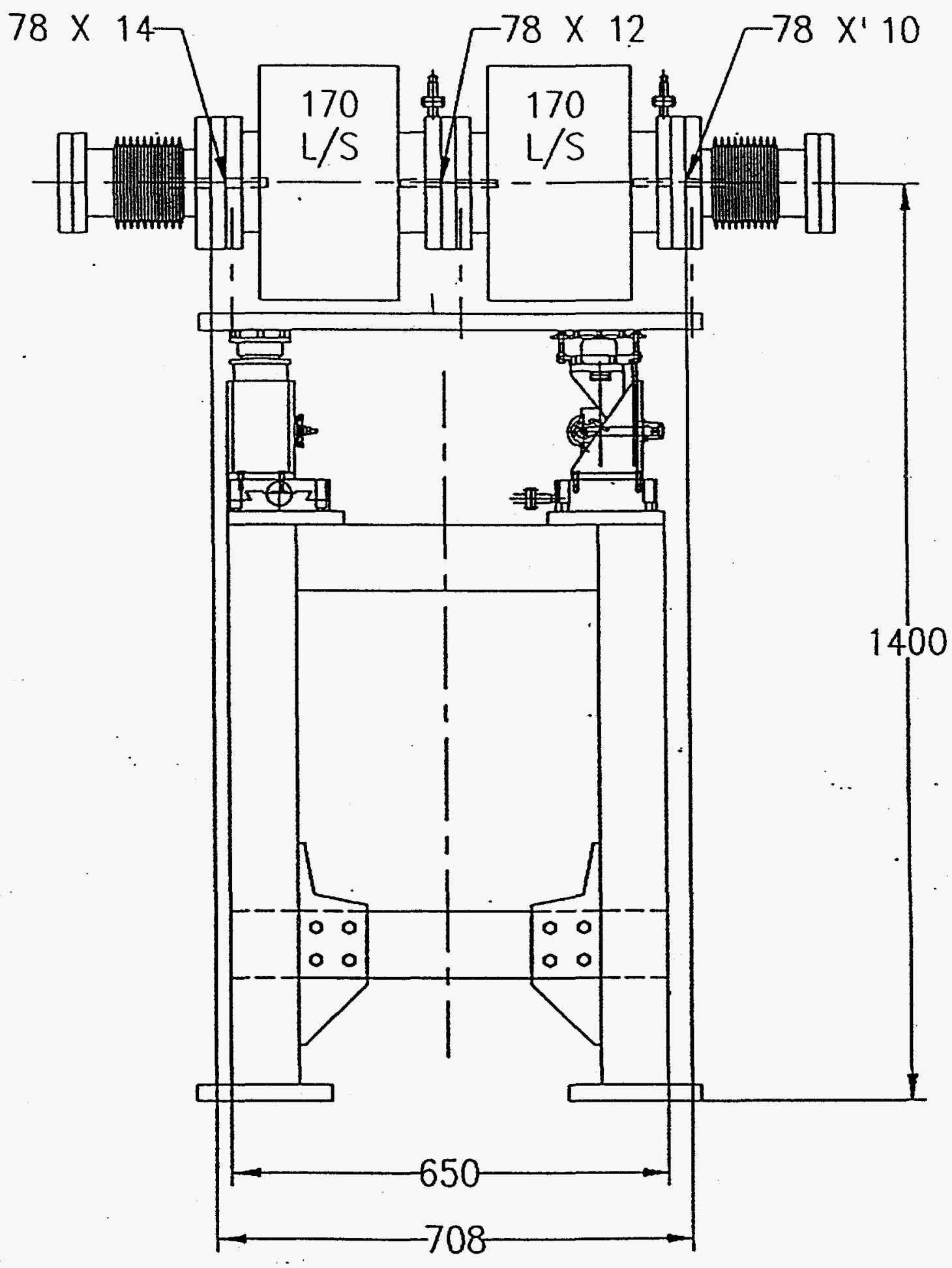

Figure 13. The APS Insertion Device Front End Differential Pump 
Figure 14. The Differential Pump Test Data and Analytical Predictions

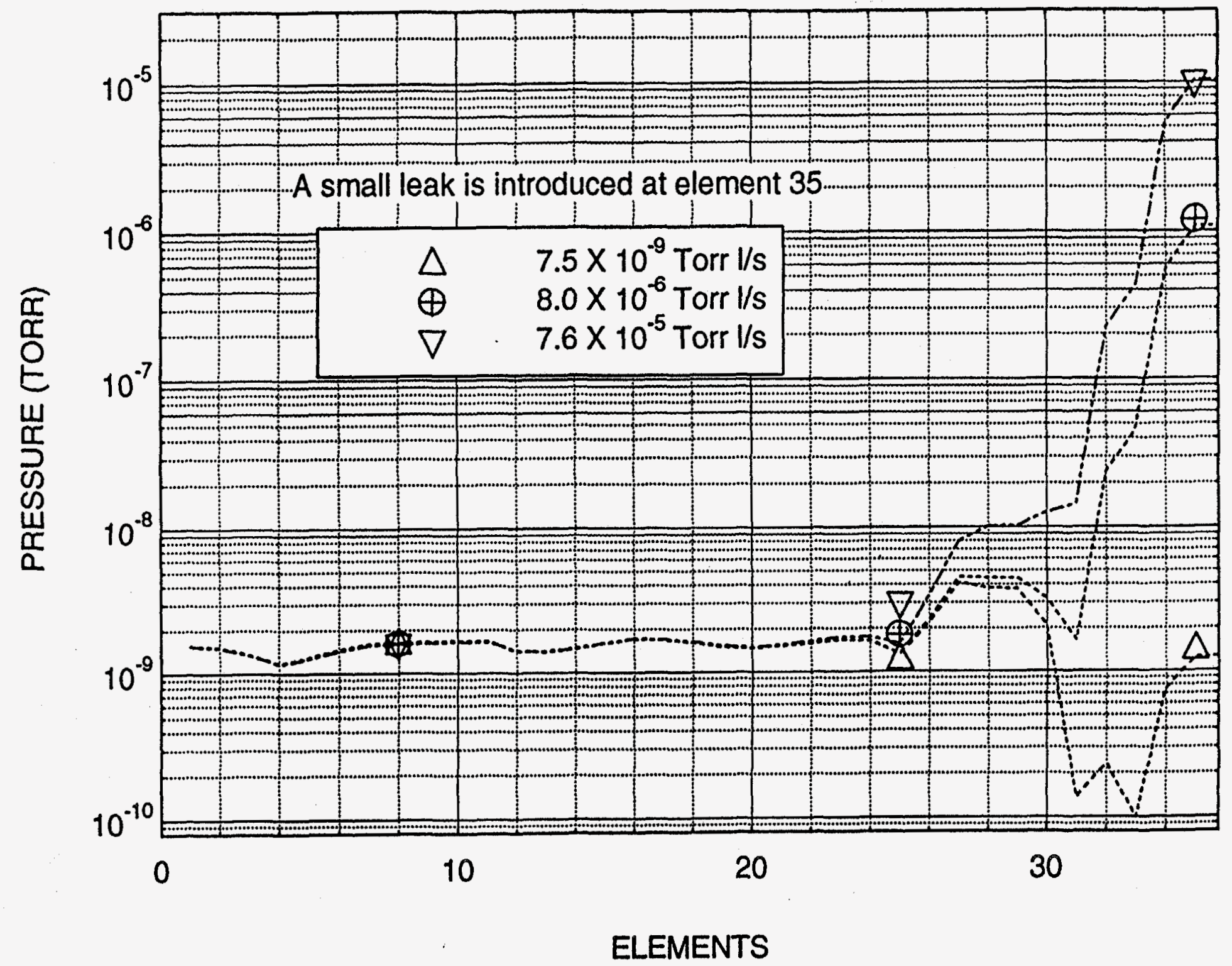

